\title{
Nuevo método molecular para diagnóstico prenatal del síndrome de Down
}

\author{
Dand and simple prenatal DNA diagnosis of Down's syndrome. \\ a L, Macdonald F, Leedham P, McConachie M, Dhanjal S, Hultén M. Lancet 1998; 352:9-12.
}

\section{Dijetivo}

Determinar la factibilidad de amplificar marcadores moleculares del cromosoma 21 ( cr 21) mediante PCR (reacción en cadena de la polimerasa), para el diagnóstico prenatal del síndrome de Down (SD).

\section{Diseño}

Estudio prospectivo "enmascarado" (los que interpretaban un test no tenían conocimiento del resultado del otro).

\section{Lugar}

Laboratorio regional citogenético en el Birmingham Heartlands Hospital, Inglaterra.

\section{Pacientes \\ Se reclutaro}

Se reclutaron 2167 mujeres embarazadas de alto riesgo. Estas fueron referidas por edad materna $\geq 35$ años, prueba de rastreo en sangre materna positiva, hallazgo ecográfico fetal anormal, o un riesgo incrementado de aberración cromosómica fetal (un niño previo con anomalía cromosómica, o un rearreglo cromosómico balanceado en un progenitor).

\section{Descripción del test en estudio y del test de referencia}

Se realizó amniocentesis a las 16-18 semanas del embarazo. De 1,5 $\mathrm{ml}$ o más del líquido se extractó ADN, se lo amplificó con PCR de 2 ó 3 marcadores STR (small-tandem-repeat markers: pequeñas repeticiones en tandem) localizados en el cromosoma 21. Se analizó en un secuenciador de ADN para identificar la presencia de dos o tres copias del cr21. La confirmación diagnóstica fue por análisis citogenético.

\section{Medición de resultados principales}

Se consideró muestra apropiada a aquella que no tenía sangre contaminante macroscópicamente. Muestra informativa fue aquella que dio un resultado con la medición de dos marcadores. El test fue positivo con la presencia de 3 picos de igual intensidad o dos picos de distinta intensidad, visualizados por inmunofluorescencia. La presencia de sangre en las muestras descartó a las mismas para el análisis (no apropiadas).

\section{Resultados}

En $2083(97,4 \%)$ de las 2139 muestras apropiadas, con 2 marcadores se obtuvo un resultado informativo y correcto; identificándose a 2053 fetos como normales y 30 como SD. De las 56 muestras apropiadas y no informativas con 2 marcadores, 41 pudieron ser reanalizadas con un tercer marcador molecular; 32 de éstas fueron informativas ( 30 normales y 2 SD). De esta manera, el $99,6 \%$ de las muestras dieron resultados informativos con estos 3 marcadores. No hubo resultados falsos positivos $n$ falsos negativos pero 28 muestras ( $1,3 \%$ del total) fueron inapropiadas para el análisis de ADN por contaminación con sangre.

\section{Conclusiones}

El análisis de ADN basado en PCR posee un gran potencial para un diagnóstico prenatal mejorado del SD, con la ventaja de disponerse los resultados en el transcurso de un día.

Fuente de financiamiento: Grant from the West Midlands NHS Executive R\&D (LORS) Programme and the NHS Executive R\&D Programme Health Technology assessment.

\section{COMENTARIO}

El diagnóstico prenatal de diversas alteraciones genéticas ha experimentado un enorme desarrollo desde la década del '70, cuando se comenzó a aplicar el estudio cromosómico de fibroblastos cultivados obtenidos por amniocentesis. La indicación principal, entonces e incluso actualmente, ha sido el riesgo incrementado para una alteración cromosómica en el feto, sobre todo la trisomía 21 indicativa del SD, aunque se pueden diagnosticar muchas otras aberraciones cromosómicas, bioquímicas y/o moleculares. Las diversas técnicas y modalidades que se han desarrollado en estos 30 años incluyen las siguientes: amniocentesis a las 16-19 semanas del embarazo con estudio citogenético, bioquímico o molecular; ammiocentesis temprana ${ }^{1}$; biopsia de vellosidad corial ${ }^{2}$; cordocentesis percutánea ${ }^{3}$; ecografía de tercer nivel ${ }^{4-5}$; rastreo en sangre materna con marcadores bioquimicos ${ }^{6-7}$; y las más recientes como el diagnóstico pre-implantación 8 y el análisis de células fetales en sangre materna. ${ }^{9}$ Se ha propuesto un análisis de decisión para determinar las probables consecuencias de aplicar las diferentes técnicas diagnósticas con fines de rastreo prenatal, desde la perspectiva de la política sanitaria en un país donde la interrupción del embarazo por motivos de enfermedad genética es aceptada. ${ }^{10}$ En nuestro país, se ha cuestionado la utilidad de ofrecer diagnóstico prenatal para tales patologías, salvo los casos, aún poco frecuentes, susceptibles de ser tratados durante el embarazo (p.ej., medicación para hiperplasia suprarrenal congénita; cirugía fetal). Sin embargo, hay varios argumentos que justifican ofrecer la posibilidad de tales estudios aún en países que no admiten el

\section{Dr. Martin Roubicek}

Hospital Privado de Comunidad. Mar del Plata, Buenos Aires, Argentina.

1. Whittle MJ. Early amniocentesis: time for a rethink. Lancet $1998 ; 351: 226-7$

2. Smidt-Jensen S. Transabdominal chorionic villus sampling. Method, safety and accuracy. Danish Med Bullefin 1998; 45:402-411

3. Shulman LP, Elias S. Percutaneous umbilical blood sampling, fetal skin sampling, and fetal liver biopsy. Semin Perinatol 1990;14:456-64

4. Taipale P et al. Increased nuchal translucency as a marker for fetal chromosomal defects. N Engl J Med 1997;337:1654-8.

5. Seeds JW. Ultrasonographic screening for fetal aneuploidy. Editorial. Id.1689-90

6. Haddow JE et al. Reducing the need for amniocentesis for women 35 years of age or older with serum markers for screening. N Engl J Med 1994;330:1114-8

(ver correspondencia en N Engl J Med 1994;331:682)

7. Haddow JE et al. Screening of maternal serum for detal Down's syndrome in the first trimester. N Engl J Med 1998:338:955-61

8. Delhanty JDA, Wells D, Harper JC. Genetic diagnosis before implantation. BMJ 1997;315:828-9

9. Bianchi DW. Prenatal diagnosis by analysis of fetal cells in maternal blood. J Pediatr 1995;127:847-56

10. Fletcher J et al. Using decision analysis to compare policies for antenatal screening for Down's syndrome. BMJ 1995;311:351-6

作 mación que pueda estar presente; la gran mayoría de los estudios dan un normal y les brindan una tranquilidad a las familias; e incluso se eviErovocados por la inseguridad o temor de tener un feto anormal. te artículo del grupo de Maj Hultén, un pionero de la citogenética desde los edosa para el diagnóstico prenatal del SD ( te otras anomalías cromosómicas). En vez de cultivar los ficual demora unos 14-20 días, se tiene resultados en el mismo día del proce. La prueba tuvo alta sensibilidad y especificidad en este estudio de ás de 2000 embarazadas. En más del $98 \%$ se arribó a un diagnóstico correcy en menos del $2 \%$ no se pudo hacer diagnóstico por contaminación con 列o se compar con los otros métodos arriba mencionados y ofrece la ventael costo inicial del método es elevado porque rede un secuenciador molecular (además del aparato para

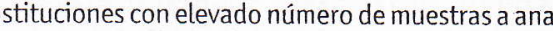
位 Es previsible que al generalizarse este tipo de análisis en el futuro, se aplique no sólo para estudios prenatales sino para un gran número de otros diagnósticos genéticos. 